Int. J. Electrochem. Sci., 11 (2016) 9599 - 9613

\title{
Effect of Sulfur Impregnation Temperature on Properties of N- Doped Activated Carbon for Supercapacitor Applications
}

\author{
Yue. Li, Ru-Quan Ren, Xiao-Juan Jin'*
}

Beijing Key Laboratory of Lignocellulosic Chemistry, MOE Engineering Research Center of Forestry Biomass Materials and Bioenergy, Beijing Forestry University, 35 Qinghua East Road, Haidian, 100083, Beijing, China.

*E-mail: 13020028853@163.com

doi: $10.20964 / 2016.11 .45$

Received: 12 June 2016 / Accepted: 9 September 2016 / Published: 10 October 2016

Sulfur-and nitrogen-co-doped activated carbons were obtained from sulfur modified nitrogen-doped activated carbons prepared from waste medium density fiberboard (MDF) prepared by $\mathrm{KOH}$ at $850^{\circ} \mathrm{C}$ for 60 minutes at a weight ratio of $3: 1$. And the sulfur was adsorbed by nitrogen-doped activated carbon with different temperatures at $300^{\circ} \mathrm{C}, 400^{\circ} \mathrm{C}, 500^{\circ} \mathrm{C}, 600^{\circ} \mathrm{C}(\mathrm{AC} 300, \mathrm{AC} 400$, AC500, AC600). The structural properties and chemical surface composition of the activated carbons were evaluated by Elemental analysis, Scanning electrical microscopy, Raman spectra, X-ray diffraction and Adsorption of nitrogen. The results showed that the content of sulfur ranging from $0.03 \mathrm{wt} \% \% 1.64 \mathrm{wt}$. \% in which the content of sulfur in AC400 (1.64 wt. \%) is highest comparing with other activated carbons. The BET specific surface area is varying from $1805 \mathrm{~m}^{2} \mathrm{~g}^{-1}$ to $2081 \mathrm{~m}^{2} \mathrm{~g}^{-1}$. The activated carbons as the electrode material which was impregnated with $7 \mathrm{M} \mathrm{KOH}$ electrolytes were characterized and tested by galvanostatic charge-discharge curves, cyclic voltammetry and alternating current impedance. The specific capacitance was improved from 225 to $264 \mathrm{~F} / \mathrm{g}$ and AC400 exhibited the best electrochemical behavior with a supreme specific capacitance $(264 \mathrm{~F} / \mathrm{g})$ and rectangular cyclic voltammetry curves.

Keywords: supercapacitor; sulfur-and nitrogen-co-doped activated carbons; temperature; waste medium density fiberboard; specific capacitance

\section{$\underline{\text { FULL TEXT }}$}

(C) 2016 The Authors. Published by ESG (www.electrochemsci.org). This article is an open access article distributed under the terms and conditions of the Creative Commons Attribution license (http://creativecommons.org/licenses/by/4.0/). 